\title{
Corrigendum: All-optical polariton transistor
}

D. Ballarini, M. De Giorgi, E. Cancellieri, R. Houdré, E. Giacobino, R. Cingolani, A. Bramati, G. Gigli \& D. Sanvitto

Nature Communications 4:1778 doi: 10.1038/ncomms2734 (2013); Published 30 Apr 2013; Updated 26 Nov 2014

In the key to Fig. 2a of this Article, the units for the control intensity were inadvertently given as $\mathrm{mW}$ instead of $\mu \mathrm{W}$. The correct version of Fig. 2 appears below.
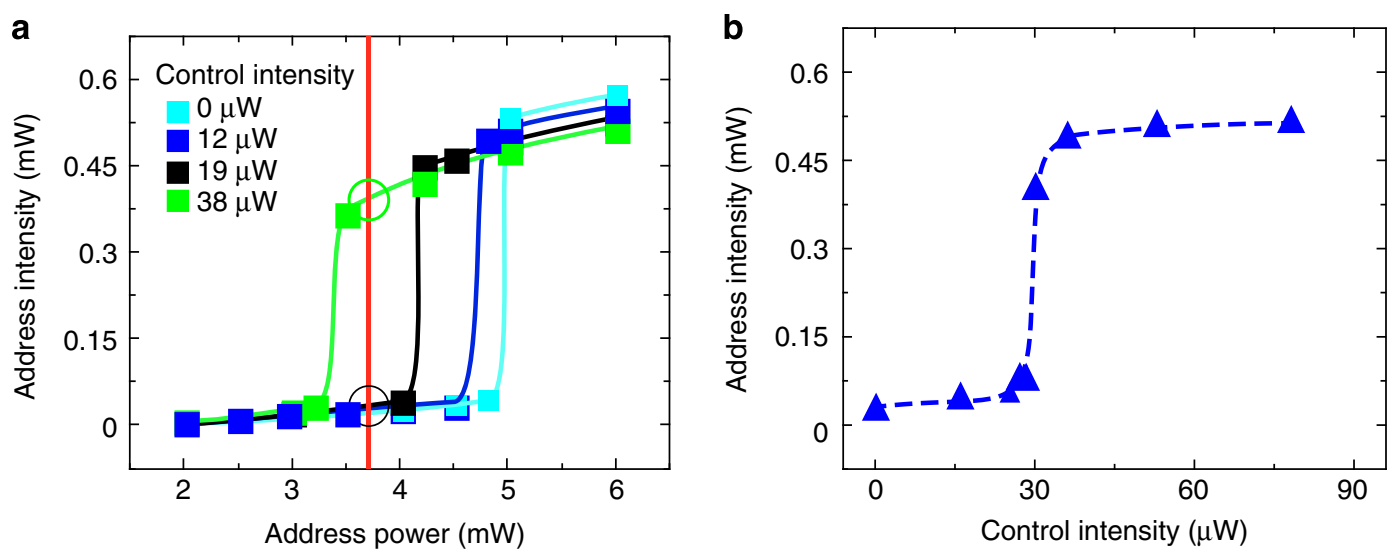

C

d
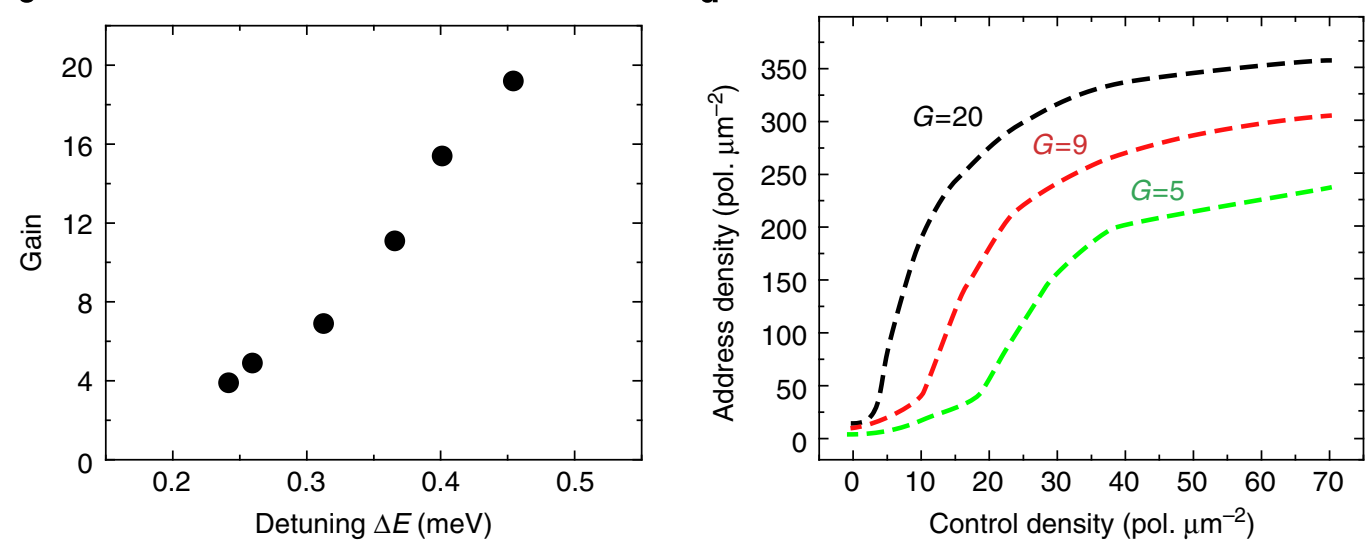

Figure 2 